05

\title{
Поверхностная и объемная проводимость диоксида ванадия
}

\author{
(C) E.A. Тутов, ${ }^{1}$ A.В. Мананников, ${ }^{1}$ H.I. Al-Khafaji, ${ }^{2}$ В.П. Зломанов ${ }^{3}$ \\ ${ }^{1}$ Воронежский государственный архитектурно-строительный университет, \\ 394006 Воронеж, Россия \\ ${ }^{2}$ College of Engineering, Al-Nahrain University, \\ Baghdad, Iraq \\ ${ }^{3}$ Московский государственный университет, \\ 119991 Москва, Россия \\ e-mail: tutov_ea@mail.ru
}

(Поступило в Редакцию 10 марта 2016 г. В окончательной редакции 22 августа 2016 г.)

На постоянном и переменном токе измерено сопротивление терморезистора ТР-68 на основе пленки диоксида ванадия, изучена температурная зависимость сопротивления в области фазового перехода полупроводник-металл в условиях адсорбционного воздействия. Предложена энергетическая зонная модель, объясняющая „,аномальный“ отклик на адсорбцию донорных газов инверсией типа проводимости поверхностных слоев диоксида ванадия.

DOI: 10.21883/JTF.2017.03.44240.1799

\section{Введение}

Фундаментальные и прикладные исследования фазового перехода полупроводник-металл в диоксиде ванадия $\left(\mathrm{VO}_{2}\right)$, впервые описанного в 1959 г. [1], продолжаются с неубывающим интересом. Комплексный характер структурно-электронных трансформаций при фазовом переходе в диоксиде ванадия приводит к тому, что микроскопическая картина явления по-прежнему остается дискуссионной [2-5]. Использование в научной литературе терминов „переход металл-изолятор“ и ,переход металл-полупроводник“ для обозначения описываемого процесса неслучайно.

По сравнению с металлом и изолятор (диэлектрик), и полупроводник характеризуются наличием запрещенной щели в энергетическом спектре носителей заряда, различаясь количественно по величине проводимости. Вместе с тем есть и качественные различия в механизмах проводимости диэлектриков и полупроводников: в диэлектриках перенос носителей заряда осуществляется по локализованным в запрещенной зоне состояниям за счет прыжкового механизма, а в полупроводниках преобладают свободные (зонные) носители заряда электроны и/или дырки, и проводимость имеет активационный механизм.

При этом полупроводник может быть как собственным, с равной концентрацией электронов и дырок (подвижность их, как правило, различна), так и примесным, с преобладающей концентрацией носителей заряда одного типа. Примесная проводимость $n$ - или $p$-типа может быть вызвана как электрически активными чужеродными атомами, так и дефектами нестехиометрии полупроводникового соединения. Диоксид ванадия называть изолятором в фазе с низкой проводимостью не совсем корректно, так как это полупроводник с не очень большой шириной запрещенной зоны $\Delta E \approx 0.6 \mathrm{eV}$.

Относительно типа носителей заряда в диоксиде ванадия до сих пор не имеется единого мнения. Большинство считает основными носителями электроны, однако некоторые авторы развивают идею о роли дырок в фазовом переходе [6,7]. Так, в работе [7] были исследованы пленки диоксида ванадия $p$-типа проводимости, и на основании измерений эффекта Холла показана смена знака носителей заряда при переходе от полупроводниковой проводимости к металлической.

Вопрос о механизме перехода дырочного полупроводника в металлическое состояние с вырожденным электронным газом имеет фундаментальное значение. Очевидно, что изменение электрофизических характеристик материала при этом не может быть монотонным.

Изучение изменений в электронном спектре диоксида ванадия при фазовом переходе имеет принципиальные сложности, так как объемные монокристаллы из-за термомеханических напряжений разрушаются за несколько циклов нагревания - охлаждения. Характеристики керамических и пленочных материалов в сильной степени зависят от условий на их внешних и внутренних поверхностях. Ситуация усложняется различными дефектами нестехиометрии поверхностных слоев и объема кристаллитов (зерна, пленки) $\mathrm{VO}_{2}$ и, как следствие, различиями в характере их проводимости.

Большое количество соединений в системе ванадийкислород [8] и легкость отклонения от стехиометрии в оксидных фазах ванадия при относительно мягких воздействиях [9] приводят к неоднозначности их электрофизических параметров, связанной как с изменениями в пределах области гомогенности соединения, так и с образованием других оксидных фаз.

При фазовом переходе полупроводник-металл наряду с электропроводностью диоксида ванадия значительно изменяются его оптические характеристики, что привлекательно для создания термохромных „умных“ стекол $[10-12]$, в том числе с использованием композитных покрытий на основе различных пленкообразователей [13] и термохромного наполнителя. Существенное 
влияние на электронную подсистему поверхностных состояний полупроводникового материала $\left(\mathrm{VO}_{2}\right)$ оказывают при этом условия на межфазных границах, определяемые химической природой контактирующих материалов. Одним из эффективных способов воздействия на электронные состояния диоксида ванадия является гидрирование [5], а также использование эффекта поля, возникающего при хемосорбции различных газов на его поверхности $[14,15]$. Роль поверхности еще больше возрастает при переходе к нанокристаллическому материалу.

В работе [16], посвященной анализу особенностей электропроводности монокристаллического $\mathrm{VO}_{2}$, сделано заключение о прыжковом механизме проводимости для низкотемпературной (диэлектрической) фазы диоксида ванадия, что обосновывается линейностью зависимости электропроводности от температуры в координатах $\ln \sigma-T$.

Как было отмечено, для практического применения эффектов, связанных с фазовым переходом в диоксиде ванадия, объемные монокристаллы малопригодны вследствие их быстрого термомеханического разрушения. Поэтому исследование механизмов переноса носителей заряда в практически важной области температур вблизи фазового перехода в керамических и пленочных материалах представляет самостоятельный интерес.

При прыжковом механизме наряду с указанной температурной зависимостью проводимости должна наблюдаться и определенная зависимость от частоты переменного тока, как правило, степенная зависимость вида $\sigma \propto \omega^{0.8}[17]$. В этом направлении исследований наиболее существенные новые результаты получены с использованием метода импедансной спектроскопии для высокоупорядоченных тонких пленок диоксида ванадия $[18,19]$.

Детальный анализ электрофизических характеристик пленок $\mathrm{VO}_{2}$ позволил авторам сделать вывод о сосуществовании полупроводниковой и металлической фаз не только в области фазового перехода, но и при более низких температурах. При этом в работе [18] наблюдалось уменьшение сопротивления пленок при частотах переменного тока выше $10 \mathrm{kHz}$, тогда как в работе [19] проводимость пленок до частот $\sim 500 \mathrm{kHz}$ оставалась практически постоянной, а при более высоких частотах уменьшалась. Такой необычный результат авторы объясняют индуктивным импедансом ультратонких включений металлической фазы $\mathrm{VO}_{2}$ нитевидной формы (filaments).

Сравнение параметров фазового перехода на постоянном и переменном токе в работе [18] показало незначительное смещение нагревательной ветви петли гистерезиса в сторону снижения температуры, практически одинаковое для всех исследованных частот; охладительная ветвь для переменного тока в работе не приведена.

Настоящая работа посвящена уточнению механизма проводимости пленочного диоксида ванадия в температурной области вблизи фазового перехода на основании измерения частотной зависимости проводимости и ее температурной зависимости на постоянном и переменном токе в условиях хемосорбции паров этанола и воды.

\section{Методика эксперимента}

В качестве объекта исследований был использован коммерческий терморезистор (ТР-68) на основе пленки диоксида ванадия, как в закрытом корпусе, так и с открытым корпусом для контакта $\mathrm{VO}_{2}$ с окружающей газовой средой.

Изменение электрического сопротивления образцов на постоянном и переменном токе (в последнем случае с помощью LCR-метра INSTEK, модель 819) изучали в интервале температур от комнатной до $100^{\circ} \mathrm{C}$. Измерения проводили в трубчатом нагревателе в потоке воздуха, создаваемом микрокомпрессором, с насыщенными парами этилового спирта (что составляет около 5\% vol.) и паров воды. Скорость нагревания и охлаждения составляла примерно $1 \mathrm{deg} / \mathrm{min}$.

При исследовании влияния адсорбции молекул воды в стационарных условиях терморезистор с открытым корпусом помещали в герметичную измерительную ячейку, для удаления паров воды из которой использовали осушитель с гранулированным мелкопористым силикагелем. Требуемые значения относительной влажности воздуха в ячейке задавали с использованием насыщенных растворов солей.

\section{Результаты и их обсуждение}

Сопротивление терморезистора при частотах до $10 \mathrm{kHz}$ практически постоянно, что свидетельствует о преобладании в проводимости $\mathrm{VO}_{2}$ при комнатной температуре делокализованных носителей заряда. В то же время для более высоких частот наблюдается уменьшение сопротивления с ростом частоты вследствие „включения“ прыжкового механизма электропереноса.

На рис. 1 приведена температурная зависимость сопротивления терморезистора на постоянном токе и переменном токе максимальной частоты $(100 \mathrm{kHz})$. В области температур от комнатной до начала фазового перехода зависимость сопротивления от температуры на постоянном токе более сильная, чем на переменном, что качественно совпадает с приведенными в [18] данными.

Основные различия в измерениях на постоянном и переменном токе наблюдаются в области петли гистерезиca, характерного для фазового перехода полупроводникметалл в диоксиде ванадия. Для терморезистора ТР68 фазовый переход с изменением сопротивления примерно на 4 порядка занимает температурный интервал около $10 \mathrm{deg}$, в отличие от результатов работы [18], где процесс изменения сопротивления на 3 порядка занимает на температурной шкале $40 \mathrm{deg}$. Для терморезистора ТР-68 при измерениях на переменном токе петля гистерезиса расширяется на несколько градусов и 


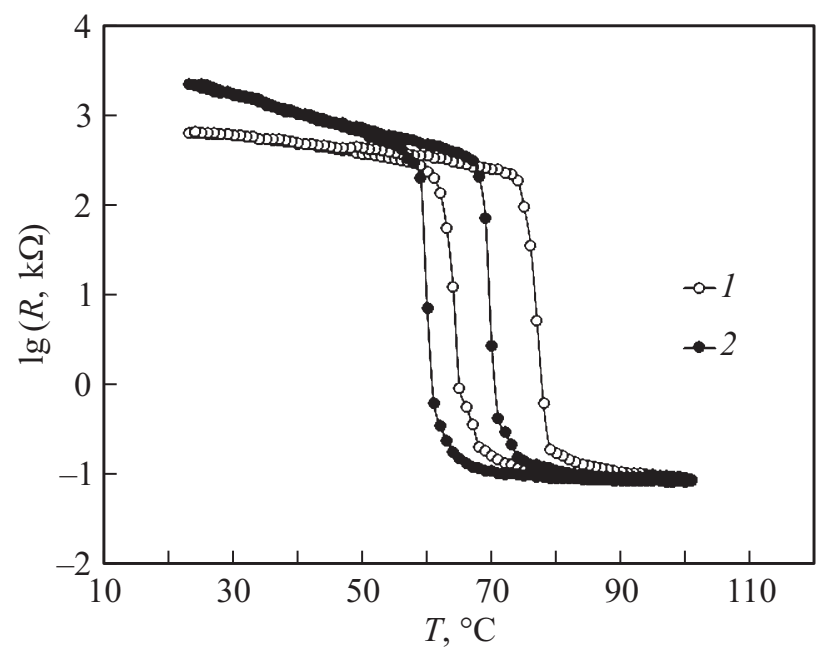

Рис. 1. Зависимость сопротивления терморезистора ТР-68 от температуры: 1 - переменный ток, 2 - постоянный ток. Правая ветвь петли гистерезиса - нагрев, левая охлаждение.

смещается в сторону более высоких температур, причем нагревательная ветвь смещена более значительно, чем охладительная.

Известно, что фазовый переход полупроводникметалл в керамическом и пленочном диоксиде ванадия представляет собой перколяционный процесс. Наблюдаемая в экспериментах по проводимости петля термического гистерезиса отражает процесс образования бесконечного проводящего кластера вблизи перколяционного порога [20,21]. Фактически происходит переход полупроводник-металл в каждом кристаллите и перколяционный переход по всей совокупности кристаллов в целом [4]. Поэтому при измерениях проводимости на переменном токе термическое положение порога протекания может зависеть от частоты измерительного сигнала.

В целом анализ параметров петли гистерезиса проводимости керамического и пленочного диоксида ванадия при измерениях на переменном токе представляет чрезвычайно сложную задачу. Тем не менее мы полагаем, что в перколяционный переход в диоксиде ванадия дают вклад как носители заряда, локализованные на дефектных центрах, так и делокализованные (зонные) носители заряда. Поэтому при температурах вблизи фазового перехода в диоксиде ванадия, по-видимому, имеет место смешанный механизм проводимости.

Измерение на переменном токе $(100 \mathrm{kHz})$ параметров перехода полупроводник-металл для терморезистора на основе пленки диоксида ванадия ( $n$-типа по знаку эффекта Зеебека) с открытым корпусом в атмосфере паров этанола (рис. 2) и воды (рис. 3) дало следующие результаты.

Добавление в поток воздуха насыщенных паров этанола приводит к повышению сопротивления диоксида ванадия в полупроводниковой фазе и, как следствие, к смещению фазового перехода в область более высоких температур в среднем на 4 deg. Охладительная ветвь петли гистерезиса смещена в сторону более высоких температур несколько меньше, так что в целом петля в атмосфере паров этанола расширяется.

Такое проявление хемосорбционного эффекта поля характерно для взаимодействия донорного газа (восстановителя) с полупроводником p-типа. Диоксид ванадия в восстановительной среде должен иметь электронную проводимость, определяемую ионами ванадия более низкой степени окисления $\left(\mathrm{V}^{+3}\right)$, однако известна его способность к окислению кислородом воздуха, и многие авторы отмечают, что на поверхности $\mathrm{VO}_{2}$ может присут-

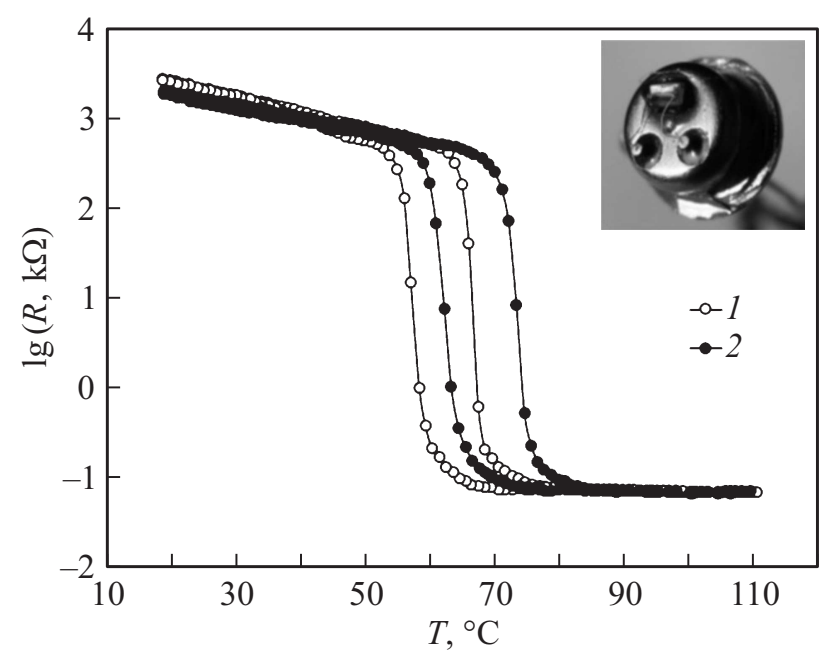

Рис. 2. Зависимость сопротивления терморезистора ТР-68 от температуры в потоке воздуха (1) и в потоке воздуха с насыщенными парами этанола (2). Правая ветвь петли нагрев, левая - охлаждение. Частота измерительного сигнала $100 \mathrm{kHz}$. На вставке - фотография терморезистора с открытым корпусом.

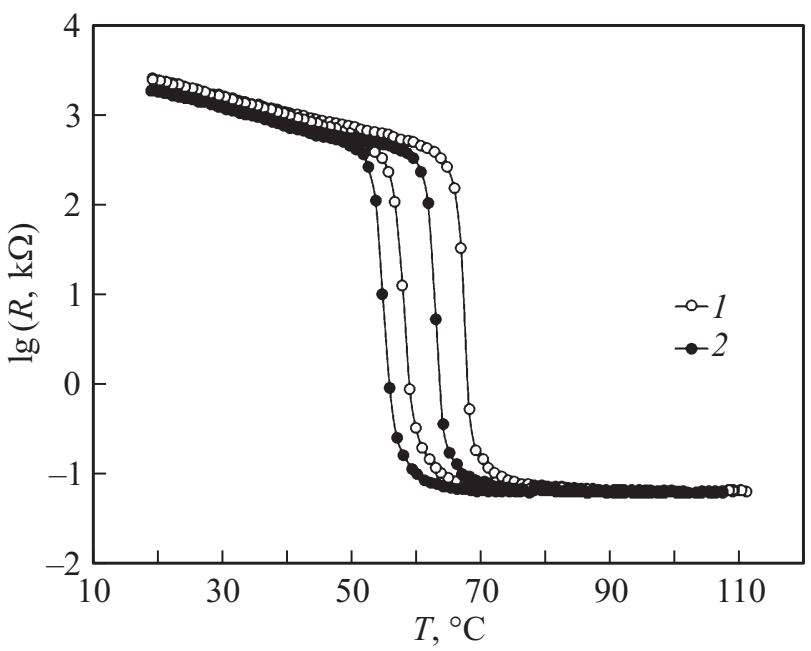

Рис. 3. Зависимость сопротивления терморезистора ТР-68 от температуры в потоке воздуха (1) и в потоке воздуха с насыщенными парами воды (2). Правая ветвь петли нагрев, левая - охлаждение. Частота измерительного сигнала $100 \mathrm{kHz}$. 
ствовать высший оксид $\mathrm{V}_{2} \mathrm{O}_{5}$. Дырочная проводимость диоксида ванадия в этом случае может быть следствием избытка аниона относительно стехиометрического количества, по крайней мере, в поверхностных слоях, которые и определяют адсорбционное взаимодействие.

В потоке воздуха с насыщенными парами воды наблюдается снижение сопротивления образца и температуры фазового перехода, также обратимое. Разнонаправленное влияние паров этанола и воды является несколько неожиданным и требует дальнейшего изучения. Заметим также некоторое различие в электрических характеристиках терморезистора с закрытым и открытым корпусом, что может быть связано с влиянием остаточной технологической атмосферы в его корпусе.

В работе [14] представлены результаты отдельного исследования влияния хемосорбции донорных и акцепторных газов на параметры фазового перехода в пленках смешанного оксида ванадия, полученных золь-гель методом [22].

Для структуры с гетерофазной пленкой, содержащей фазу $\mathrm{VO}_{2}(\mathrm{~B})$, при исследовании температурной зависимости сопротивления на постоянном и переменном токе наблюдались характерные для фазового перехода ступенчатое изменение проводимости и петля гистерезиса в интервале температур $50-70^{\circ} \mathrm{C}$. Суммарное изменение сопротивления структуры при фазовом переходе в диоксиде ванадия было не слишком значительным (2.5-3 раза), что связано с протеканием тока по другим фазам оксидов ванадия.

Ширина петли гистерезиса для фазового перехода в диоксиде ванадия составила примерно $15 \mathrm{deg}$. Хемосорбция паров этанола смещала фазовый переход в область высоких температур более чем на $10 \mathrm{deg}$, при этом петля гистерезиса становилась заметно шире (примерно на $4 \mathrm{deg}$ ). Общее сопротивление структуры повышалось.

Озон сравнительно невысокой концентрации (на уровне $10 \mathrm{ppb}$ ) влияет на фазовый переход менее значительно и в противоположном направлении - несколько снижает температуру перехода и сопротивление пленки в целом.

Исследованные пленки оксида ванадия проявили достаточную стабильность в условиях термоциклирования в окислительно-восстановительной атмосфере без заметной деградации электрических характеристик.

О механизме влияния хемосорбции донорных и акцепторных газов на параметры фазового перехода полупроводник-металл в диоксиде ванадия можно высказать следующие предположения. На поверхности пленки $\mathrm{VO}_{2}$-типа проводимости в результате сорбции атмосферного кислорода в принципе может образовываться инверсионный слой (с дырочной проводимостью), сопротивление которого в восстановительной атмосфере должно повышаться, что и наблюдается в эксперименте. Озон лишь незначительно усиливает действие кислорода.

На рис. 4 показана качественная зонная модель поверхностного слоя диоксида ванадия, позволяющая

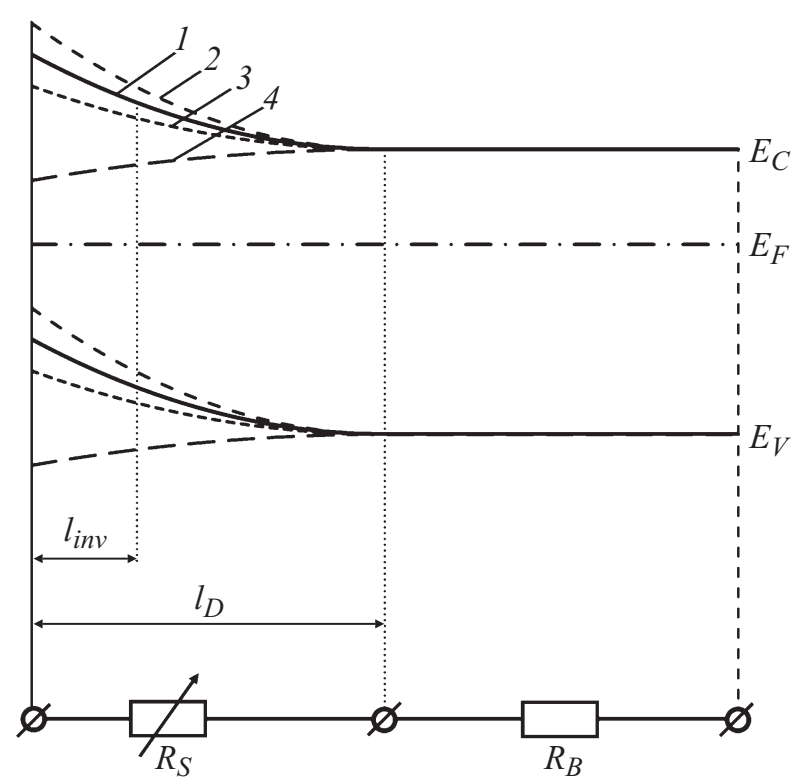

Рис. 4. Качественная зонная модель поверхности $\mathrm{VO}_{2}$ в условиях хемосорбции газов: $1-$ воздух, $2-$ воздух с озоном, 3 - воздух с парами этанола, 4 - воздух с парами воды. $E_{C}-$ энергия дна зоны проводимости, $E_{F}-$ энергия Ферми, $E_{V}-$ энергия потолка валентной зоны, $l_{D}-$ длина экранирования Дебая, $l_{i n v}$ - толщина инверсионного слоя, $R_{S}$ - сопротивление поверхностного слоя ( $n$ - или $p$-типа проводимости), $R_{B}-$ сопротивление объемного слоя диоксида ванадия ( $n$-типа проводимости).

объяснить совокупность наблюдаемых результатов. Измеряемая величина сопротивления диоксида ванадия складывается из сопротивления объемного слоя $\left(R_{B}\right)$ и поверхностного слоя $\left(R_{S}\right)$. Последнее может существенно изменяться (увеличиваться или уменьшаться) при хемосорбции газов - доноров или акцепторов электронов (восстановителей или окислителей соответственно).

При переходе проводимости поверхностного слоя диоксида ванадия от дырочного типа к электронному типу (через область собственной проводимости) в восстановительной атмосфере сопротивление пленки должно изменяться немонотонно. Эксперимент подтверждает это предположение (рис. 5).

В соответствии с предложенной зонной моделью, молекулы воды, адсорбированные на поверхности пленки диоксида ванадия, проявляют свойства донора электронов. При относительной влажности $p / p_{s}$ до $12 \%$ сопротивление инверсионного слоя ( $p$-типа) возрастает, но с дальнейшим увеличением $p / p_{s}$ толщина этого слоя уменьшается, и весь диоксид ванадия становится электронным. Молекулы воды при невысокой температуре $\left(20^{\circ} \mathrm{C}\right)$ оказываются более „сильным“ донором электронов, чем молекулы этанола, вследствие их большого дипольного момента.

Аналогичная немонотонность в изменении оптических свойств при электрохимически индуцированном фазовом переходе в диоксиде ванадия была обнаружена ранее [23]. 


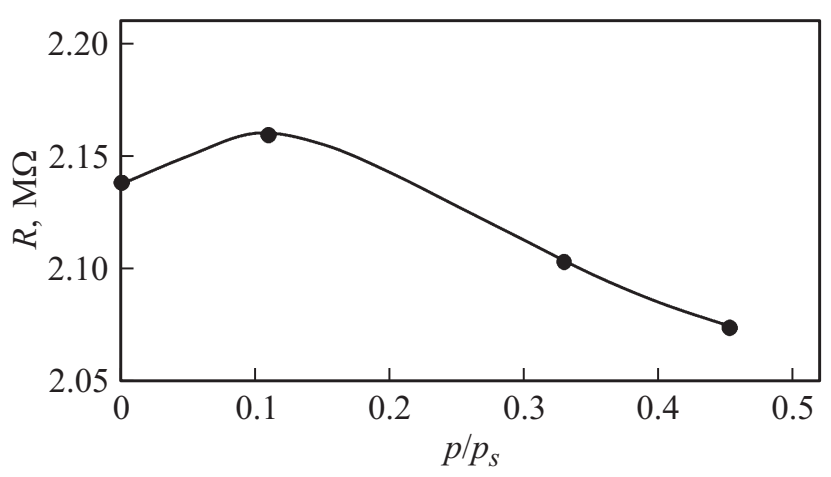

Рис. 5. Зависимость сопротивления терморезистора ТР-68 от относительной влажности воздуха при температуре $20^{\circ} \mathrm{C}$.

Исследование влияния адсорбционных воздействий на электрофизические характеристики пленок диоксида ванадия в условиях предварительного вакуумирования [24] показало ожидаемое для полупроводника $n$ типа поведение. Хемосорбция атмосферного кислорода (в зависимости от длительности и температуры воздействия), по-видимому, может приводить к образованию на поверхности диоксида ванадия инверсионного слоя с дырочной проводимостью.

Для гетерофазных пленок влияние хемосорбции газов на положение и форму петли гистерезиса может быть связано не только с процессами непосредственно в диоксиде ванадия, но и с изменениями в фазах других оксидов (например, дегидратацией пентаоксида ванадия в парах этанола или окислением-восстановлением $\mathrm{V}_{6} \mathrm{O}_{13}$ ).

\section{Заключение}

Таким образом, на постоянном токе и переменном токе в диапазоне частот $12-100 \mathrm{kHz}$ измерено сопротивление серийно выпускаемого терморезистора ТР68 на основе пленки $\mathrm{VO}_{2}$. На постоянном токе и на частоте $100 \mathrm{kHz}$ измерена температурная зависимость сопротивления в диапазоне температур, включающем область фазового перехода.

Анализ полученных результатов позволяет заключить, что в этой температурной области проводимость полупроводниковой фазы диоксида ванадия осуществляется как по прыжковому, так и по зонному механизму. При работе терморезистора на переменном токе наблюдается расширение петли температурного гистерезиса.

Хемосорбция (включая изменение количества адсорбированного на пленке $\mathrm{VO}_{2}$ атмосферного кислорода) влияет, по-видимому, как на концентрацию зонных носителей заряда, так и изменяет параметры дефектных центров, участвующих в проводимости по прыжковому механизму.

В настоящей работе на примере паров этанола и воды показано, что с помощью хемосорбции газов можно обратимо управлять параметрами фазового перехода полупроводник-металл в пленках диоксида ванадия.

\section{Список литературы}

[1] Morin F.J. // Phys. Rev. Lett. 1959. Vol. 3. N 1. P. 34-36.

[2] Шадрин Е.Б, Ильинский А.В. // ФТТ. 2000. Т. 42. Вып. 6. C. $1092-1099$.

[3] Ильинский А.В., Квашенкина О.Е., Шадрин Е.Б. // ФТП. 2012. Т. 46. Вып. 4. С. 439-446.

[4] Ильинский А.В., Квашенкина О.Е., Шадрин Е.Б. // ФТП. 2012. Т. 46. Вып. 9. С. 1194-1208.

[5] Ильинский А.В., Квашенкина О.Е., Шадрин Е.Б. // ФТП. 2011. Т. 45. Вып. 9. С. 1197-1202.

[6] Kim H.-T., Kim B.-J., Lee Y.W., Chae B.-G., Yun S.J. // Physica B: Conden. Matter. 2008. Vol. 403. N 5-9. P. 1434-1436.

[7] Kim H.-T., Chae B.-G., Youn D.-H., Maeng S.-L., Kim G., Kang K.-Y., Lim Y.-S. // New J. Physics. 2004. Vol. 6. N 52. P. 1-19.

[8] Wriedt H.A. // Bull. Of Alloy Phase Diagrams. 1989. Vol. 10. N 3. P. 271-277.

[9] Griffiths C.H., Eastwood H.K. // J. of Appl. Phys. 1974. Vol. 45. N 5. P. 2201-2206.

[10] Blackman C.S., Piccirillo C., Binions R., Parkin I.P. // Th. Sol. Films. 2009. Vol. 517. P. 4565-4570.

[11] Warwick M., Binions R. // J. Mater. Chem. A. 2014. Vol. 2. P. 3275-3292.

[12] Gao Y., Luo H., Zhang Z., Kang L., Chen Z., Du J., Kanehira M., Cao C. // Nano Energy. 2012. Vol. 1. P. 221246.

[13] He T., Yao J. // Progr. Mater. Sci. 2006. Vol. 51. P. 810-879.

[14] Тутов Е.А., Зломанов В.П. // ФТТ. 2013. Т. 55. Вып. 11. C. 2233-2236.

[15] Tutov E.A., Kryukov P.I., Zlomanov V.P. // Smart Nanocomposites. 2013. Vol. 4. P. 75-77.

[16] Андреев В.Н., Климов В.А. // ФТТ. 2007. Т. 49. Вып. 12. C. 2146-2150.

[17] Mott N.F., Davis E.A. Electronic Processes in Non-Crystalline Materials. Oxford, 2012. 605.

[18] Zhong X., LeClair P., Sarker S.K., Gupta A. // Phys. Rev. B. 2012. Vol. 86. P. 094114-1-094114-7.

[19] Ramirez J.-G., Schmidt R., Sharoni A., Gomez M.E., Schuller I.K., Patino E.J. // Appl. Phys. Lett. 2013. Vol. 102. P. 063110-1-063110-4.

[20] Gentle A.R., Smith G.B., Maaroof A.I. // J. Nanophoton. 2009. Vol. 3. N 031505. P. 1-15.

[21] Gurvitch M., Luryi S., Polyakov A., Shabalov A. // IEEE Transactions on Nanotechnology. 2010. Vol. 9. N 5. P. $647-$ 652.

[22] Berezina O., Kirienko D., Pergament A., Stefanovich G., Velichko A., Zlomanov V. // Th. Sol. Film. 2015. Vol. 574. P. 15-19.

[23] Chenevas-paule A. // J. Phys. Colloques. 1976. Vol. 37. N C4. P. C4-75-C4-77.

[24] Киселев В.Ф., Козлов С.Н., Левшин Н.Л., Смирнов Н.И. // ФТТ. 1988. Т. 30. Вып. 3. С. 924-926. 